\title{
LA-UR-16-23095
}

Approved for public release; distribution is unlimited.

Title: State-of-the-art in Manufacturing Pyrochemical Processing Crucibles

Author(s): $\quad$ Parkinson, David Allen

Intended for: $\quad$ UNM ME 586 Class Graduate Student Presentation

Issued: 2016-05-03 
Disclaimer:

Los Alamos National Laboratory, an affirmative action/equal opportunity employer, is operated by the Los Alamos National Security, LLC for the National Nuclear Security Administration of the U.S. Department of Energy under contract DE-AC52-06NA25396. By approving this article, the publisher recognizes that the U.S. Government retains nonexclusive, royalty-free license to publish or reproduce the published form of this contribution, or to allow others to do so, for U.S. Government purposes. Los Alamos National Laboratory requests that the publisher identify this article as work performed under the auspices of the U.S. Department of Energy. Los Alamos National Laboratory strongly supports academic freedom and a researcher's right to publish; as an institution, however, the Laboratory does not endorse the viewpoint of a publication or guarantee its technical correctness. 


\section{State-of-the-art in Manufacturing Pyrochemical Processing Crucibles}

David A. Parkinson

May 5, 2016 


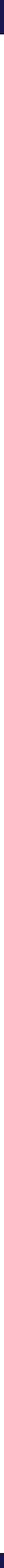




\section{Pyrochemical Processing at Los Alamos}

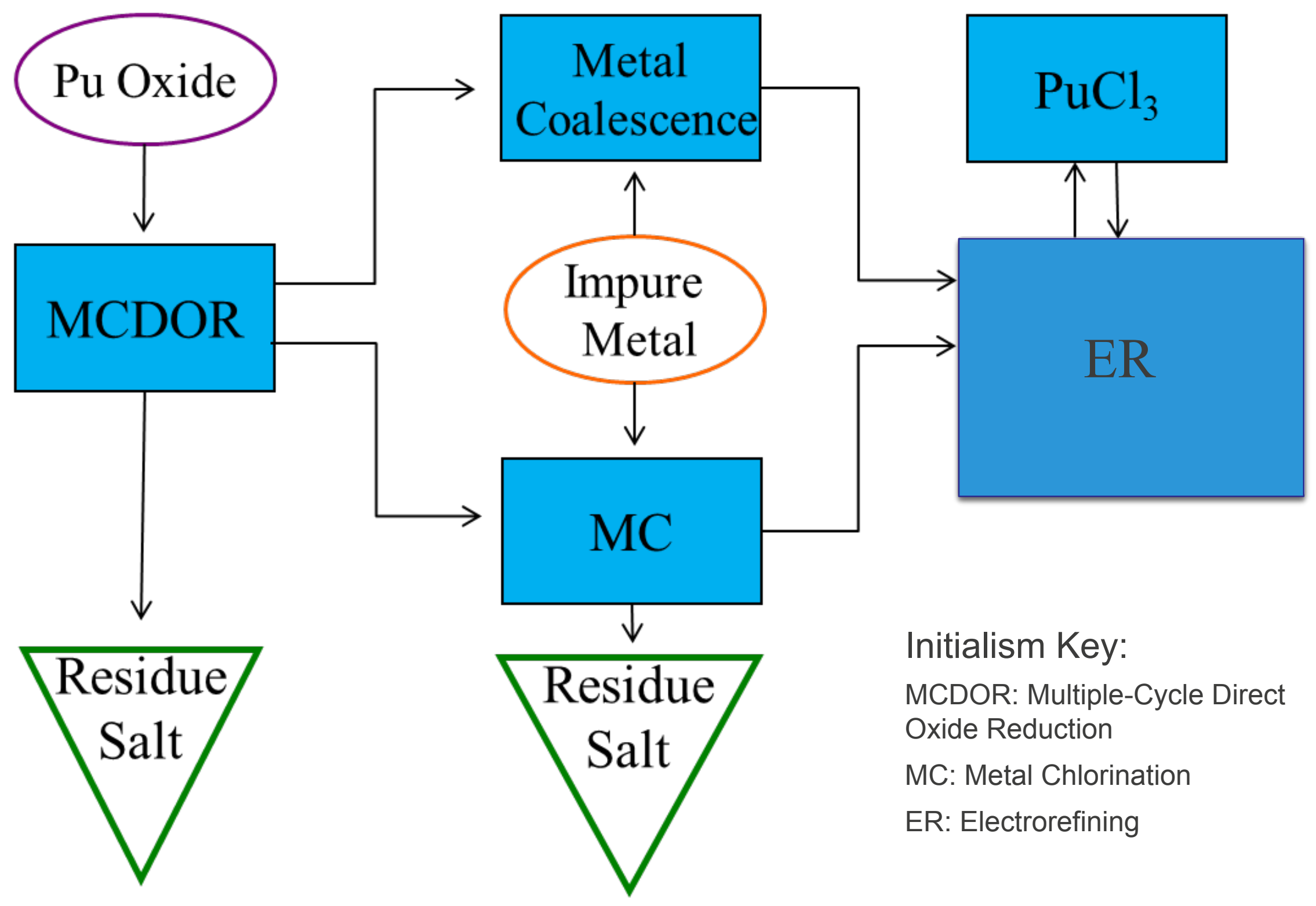




\section{Pyrochemical Processing at Los Alamos}

- High temperature processes $\left(700-900{ }^{\circ} \mathrm{C}\right)$

- Molten salts and reactive metals $\left(\mathrm{MgCl}_{2}, \mathrm{CaCl}_{2}, \mathrm{Pu}, \mathrm{Ca}\right)$

- $\mathrm{Cl}_{2}$ gas used in DOR and MC

- Design of pyrochemical processing equipment is an intriguing technical challenge 


\section{Pyrochemical Processing at Los Alamos}

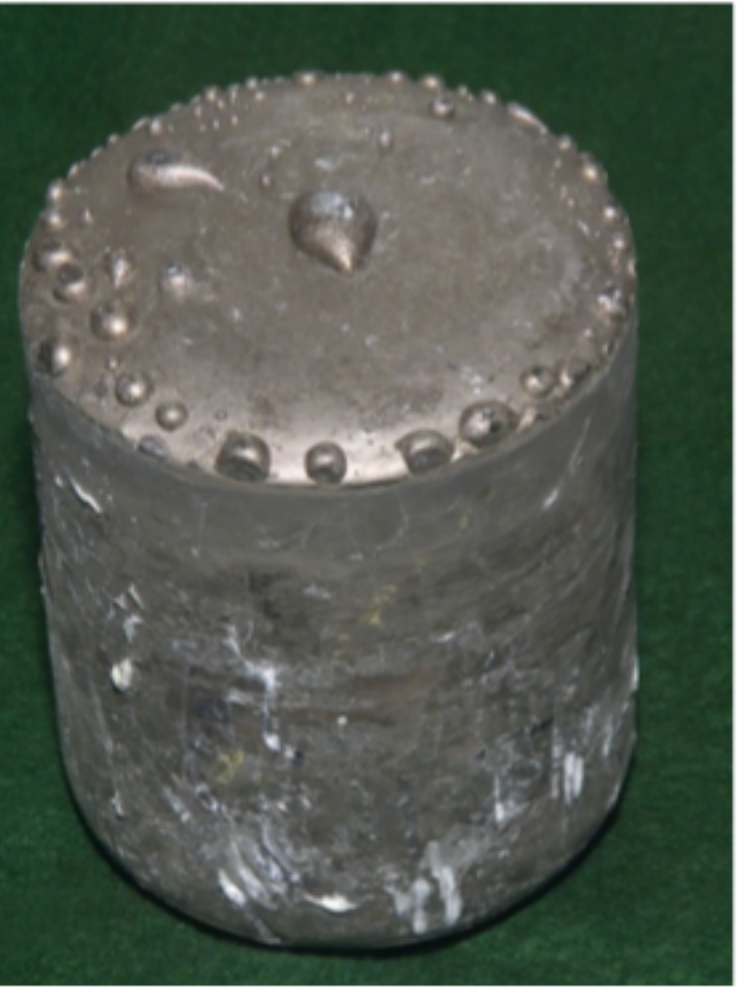

Coalescence/MC Ingot (Feed for $E R$ )

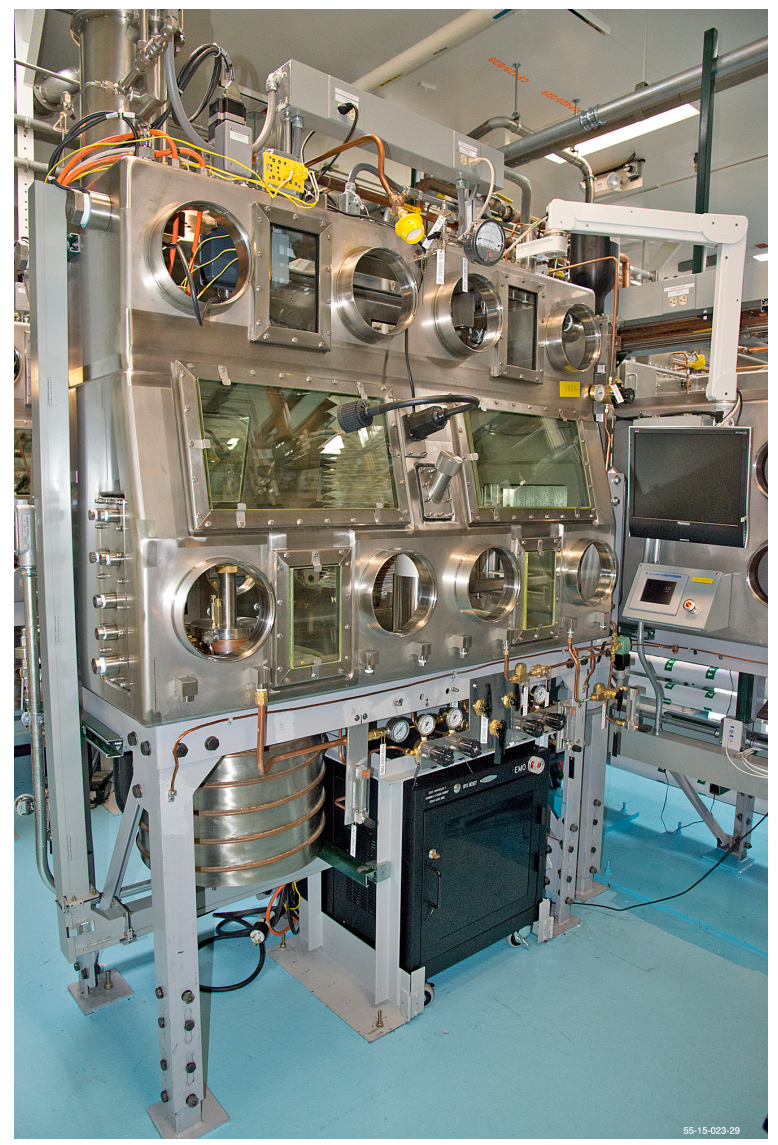

ER Glovebox

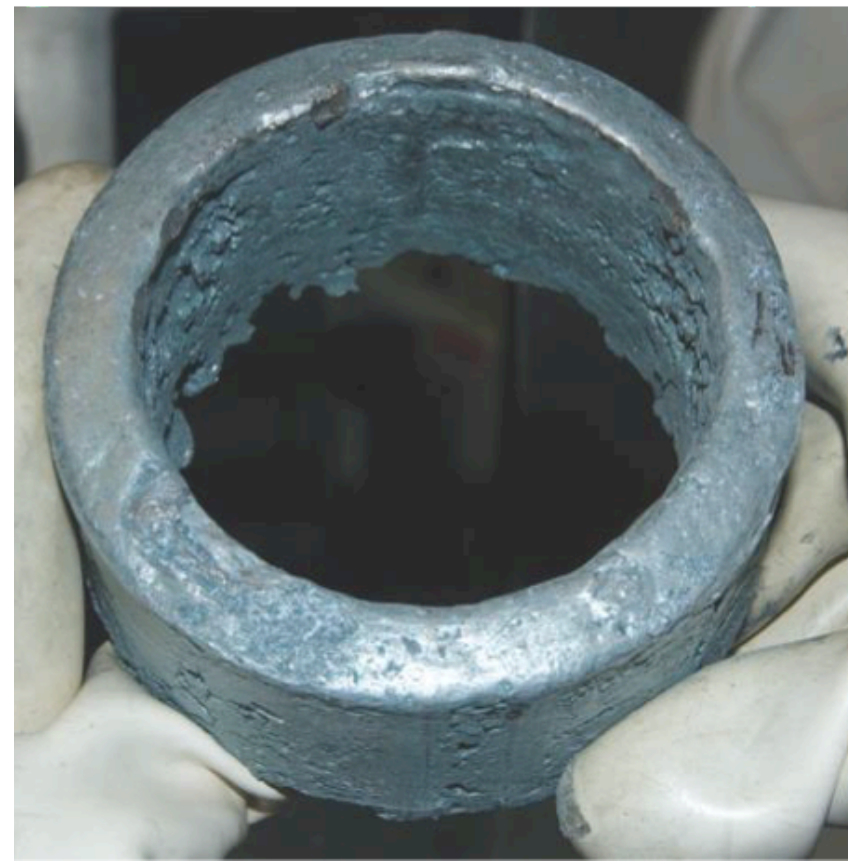

ER Plutonium Ring 


\section{Design for Manufacturability Principles}

- Boothroyd, Dewhurst, and Knight (2002) recommend reducing the amount of parts in an assembly (p. 93).

- According to B\&D\&K (2002) analysis, individual part assembly times are based on handling and insertion of the parts (p. 86). Handling and insertion should be simplified.

- Correct materials and processes for manufacture should also be considered according to B\&D\&K (2002): "because material and process combinations are likely to be chosen from those with which designers are most comfortable, the possibilities of using other processes that may be much more cost effective may be missed" (p. 44). 


\section{Current Crucible Design and ER Process}

$\frac{1}{8}$
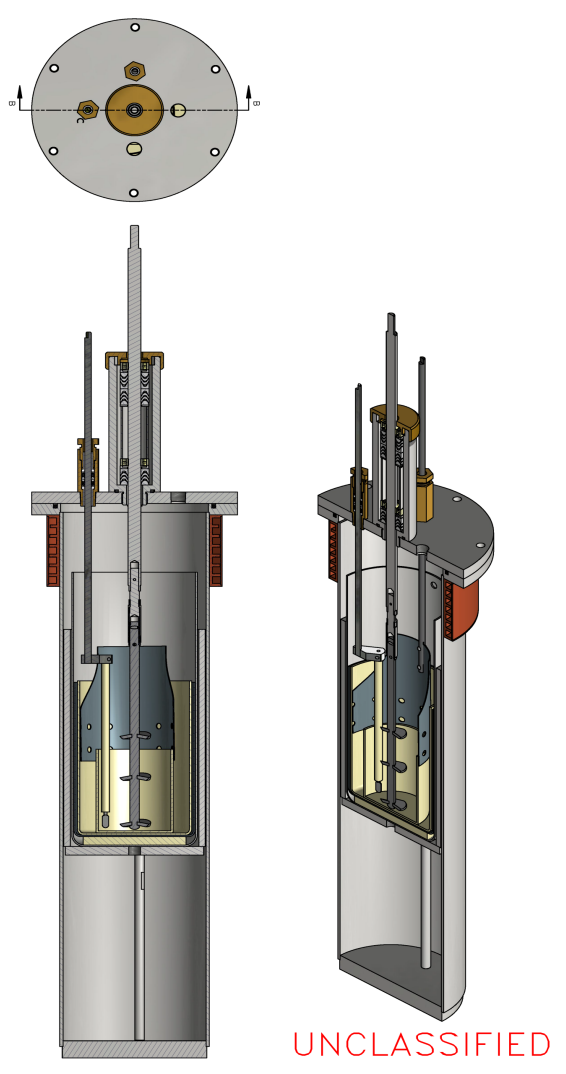

ER Processing Equipment

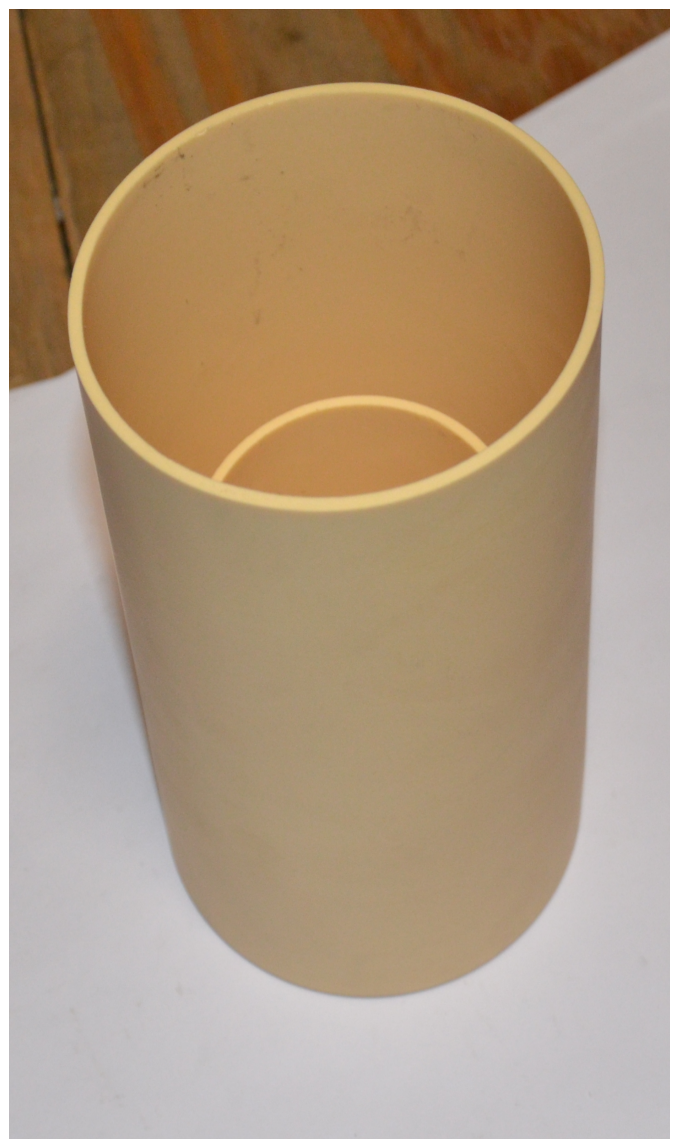

ER Crucible

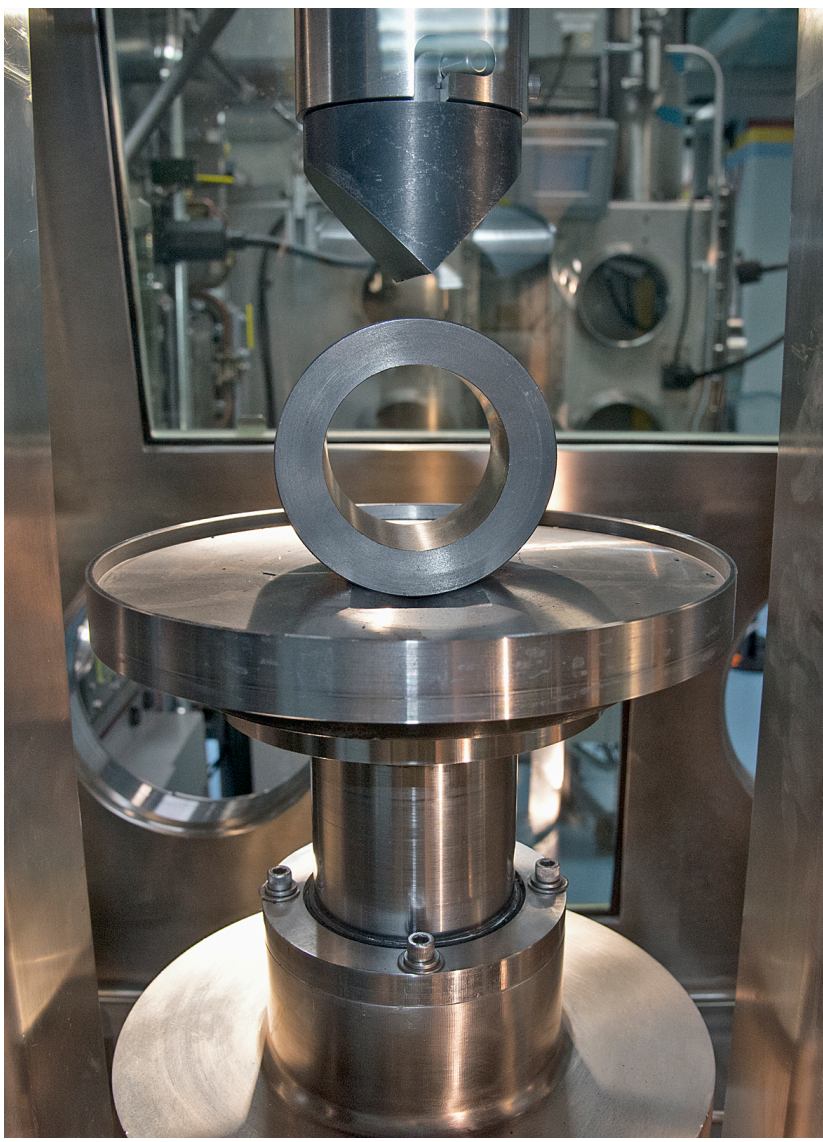

Breaking Press with Representative Ring 


\section{Current Crucible Design and ER Process}

- Minimize part count by making the crucible as one part instead of as an assembly of two parts

- Combine the anode and cathode with the crucible as one part

- Find the "Holy Grail": the reusable crucible

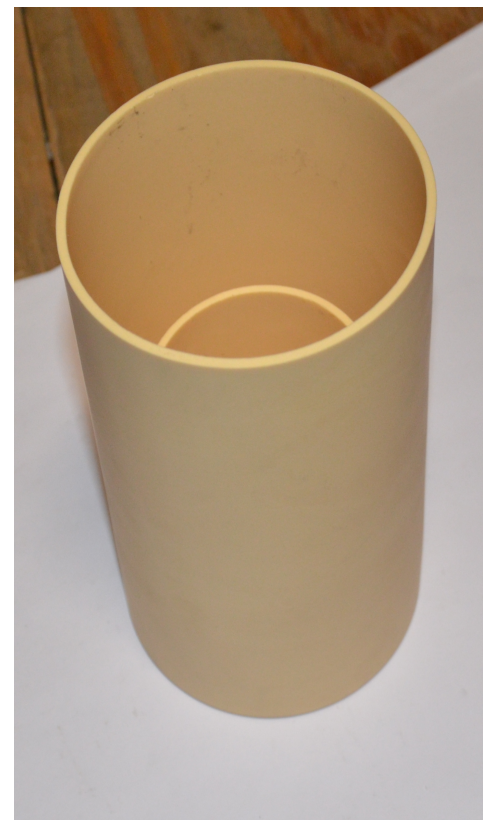




\section{Crucible Material}

- Alumina crucible would be easier to manufacture and could reduce the amount of salt required (Paget, Watson and Campbell-Kelly 2014).

- Silicon Nitride held up better in corrosion studies with $\mathrm{CaCl}_{2}$ and $\mathrm{Cl}_{2}$ than MgO (McLaughlin, Sessions and Marra 1990).

- A tantalum carbon alloy could possibly be reused (Bronson, Dodson and Riley 1994). 


\section{D Printing}

- Uwe Scheithauer et al. (2015) \& thermoplastic 3D printing.
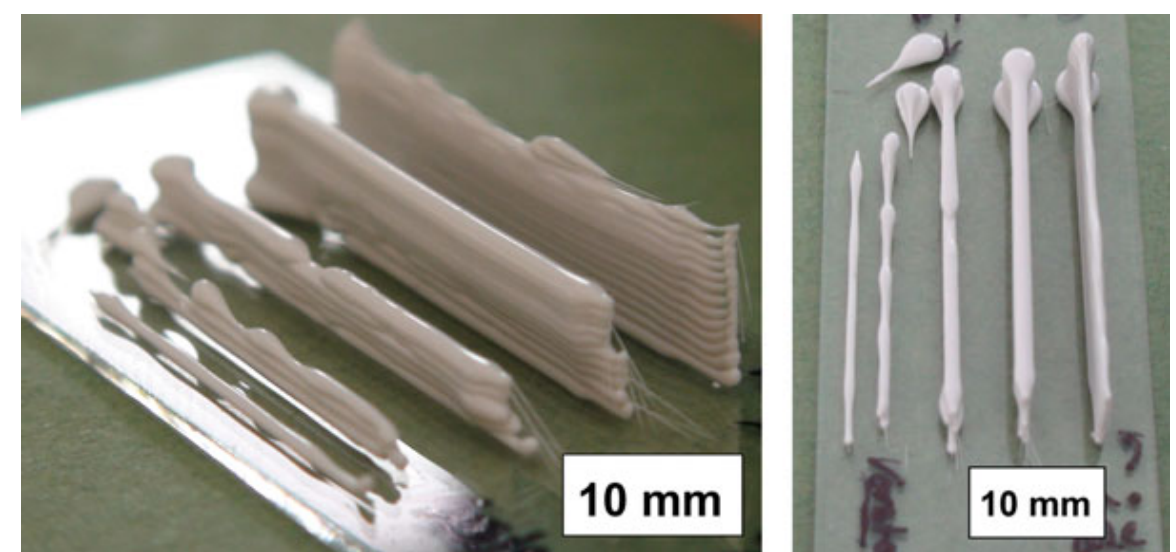

Uwe Scheithauer et al. (2015)
- Xiangming Li et al. (2012) investigated the mechanical properties of a 3D printed, pressurelesssintered silicon nitride $\left(\mathrm{Si}_{3} \mathrm{~N}_{4}\right)$

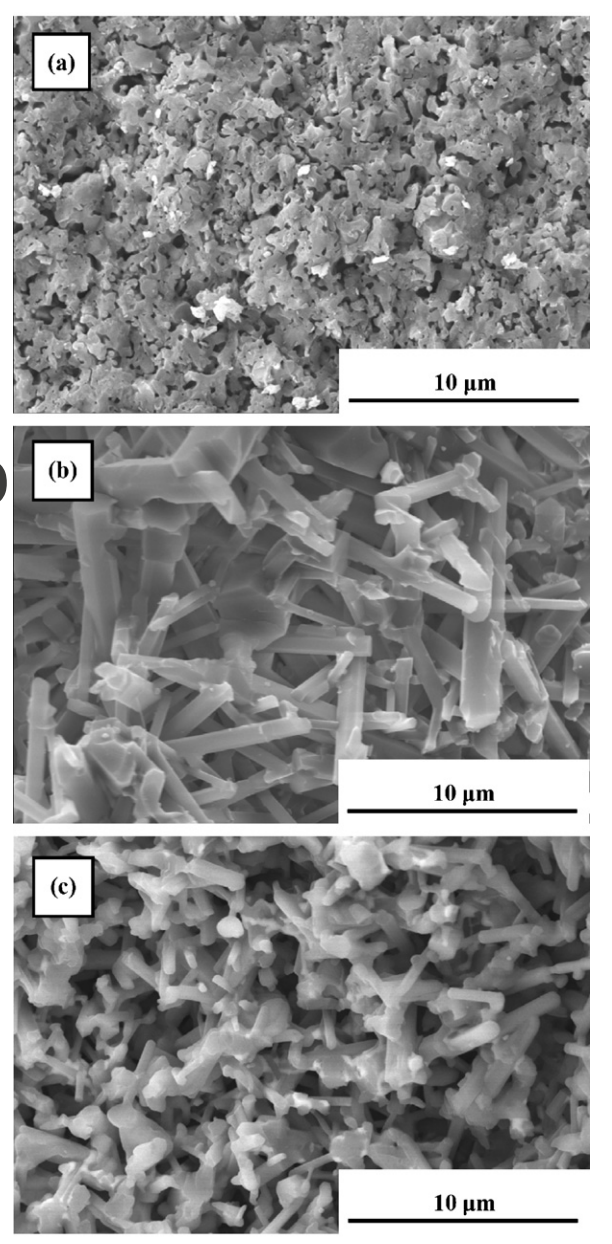

Xiangming Li et al. (2012) 


\section{Conclusions and Recommendations}

- Make crucible into a single part

- Possibly combine anode and cathode with crucible

- Investigate alumina, silicon nitride, and tantalum carbon alloy

- 3D print a crucible and test

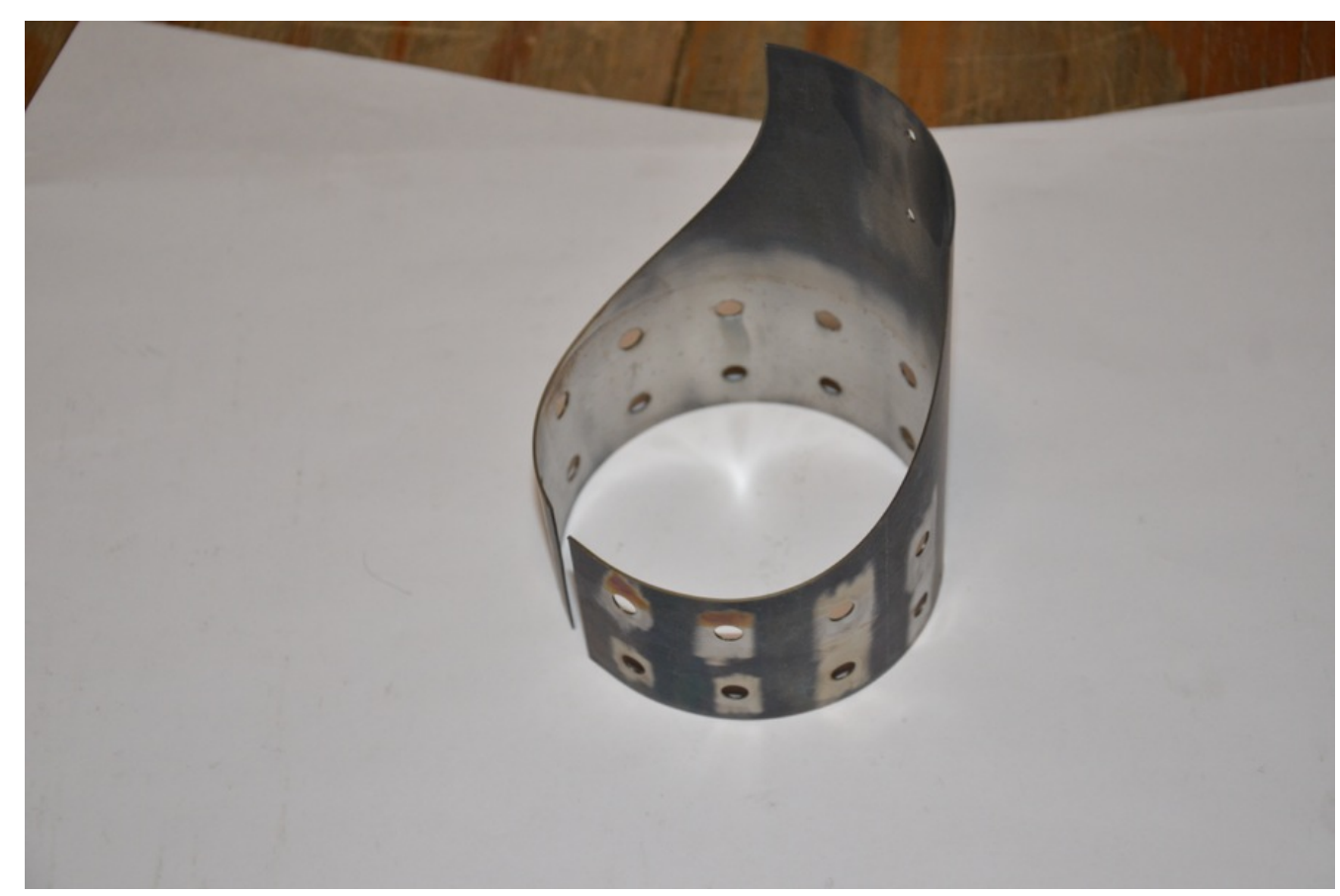




\section{References}

- Boothroyd, Geoffrey, Peter Dewhurst, and Winston Knight. Product Design for Manufacture \& Assembly. 2nd Edition. Boca Raton, Florida: Taylor and Francis Group, 2002.

- Bronson, M.C., K.E. Dodson, and D.C. Riley. "Advanced Pyrochemical Technologies for Minimizing Nuclear Waste." Transactions of the American Nuclear Society 70 (1994): 95-96.

- Li, Xiangming, Litong Zhang, and Xiaowei Yin. "Microstructure and mechanical properties of three porous $\mathrm{Si}_{3} \mathrm{~N}_{4}$ ceramics fabricated by different techniques." Materials Science and Engineering A, no. 549 (2012): 43-49.

- Navratil, James D. "Plutonium and Americium Processing Chemistry and Technology." Inorganica Chimica Acta 94 (1984): 263-269.

- McLaughlin, David F., Charles E. Sessions, and John E. Marra. Corrosion Studies in Molten Calcium Chloride with Chlorine. Slides and remarks proposed for presentation at ANS Winter Meeting 1990, Westinghouse Science and Technology Center, Aiken: Westinghouse Savannah River Company, 1990.

- Moser, W. Scott, and James D. Navratil. "Review of Major Plutonium Pyrochemical Technology." Journal of the Less-Common Metals 100 (1984): 171-187.

- Paget, Timothy J., Robert F. Watson, and Rob P. Campbell-Kelly. "Management of Salt within Plutonium Electrorefining." 38th Actinide Separations Conference. Albuquerque: Los Alamos National Laboratory, 2014. 84.

- Scheithauer, Uwe, Eric Schwarzer, Hans-Jürgen Richter, and Tassilo Moritz. "Thermoplastic 3D Printing-An Additive Manufacturing Method for Producing Dense Ceramics." International Journal of Applied Ceramic Technology 12, no. 1 (2015): 26-31. 